\title{
Correction to: An adolescent male with acute kidney injury: answers
}

\section{Angelina Dixon ${ }^{1} \cdot$ Courtney Styres $^{2} \cdot$ Isa Ashoor $^{2} \cdot$ Randall Craver $^{2}$}

Published online: 22 June 2020

(C) IPNA 2020

\section{Correction to: Pediatr Nephrol} https://doi.org/10.1007/s00467-020-04498-3

The authors regret that the name of the author Randall Craver was incorrectly rendered as "Randall Carver." The original article has been corrected.

Publisher's note Springer Nature remains neutral with regard to jurisdictional claims in published maps and institutional affiliations.

The online version of the original article can be found at https://doi.org/ 10.1007/s00467-020-04498-3

Angelina Dixon

adixon5@tulane.edu

1 Department of Internal Medicine and Pediatrics, Tulane University School of Medicine, New Orleans, LA, USA

2 Department of Pediatrics, Louisiana State University School of Medicine, New Orleans, LA, USA 